Скрипчинский А.В., Северо-Кавказский федеральный университет, г. Ставрополь, Россия, Ron1975@list.ru

Антонов C.A. Северо-Кавказский федеральный научный аграрный центр, г. Михайловск, Россия, santosb@mail.ru

\title{
КОСМИЧЕСКИЙ МОНИТОРИНГ ПАСТБИЩ ВОСТОЧНЫХ РАЙОНОВ СТАВРОПОЛЬСКОГО КРАЯ
}

Введение:

Материалы и методы

В результате дефицита пашни в Ставропольском крае происходит трансформация сельскохозяйственных земель. Выявить масштабы распашки пастбищ возможно на основе пространственно-временного анализа сельскохозяйственных угодий посредством геоинформационных систем с использованием космической информации. исследования:

На основе данных с космических аппаратов серии Landsat в период с января 1990 года по декабрь 2018 года производилось визуальное дешифрирование пастбищ. Уточнение выявляемых территорий пастбищ производилось с использованием индексных изображений коэфрицииента NDVI

Результаты и их обсуждение:

В Буденновском районе Ставропольского края пастбища располагаются преимущественно по долинам рек. В Арзгирском районе Ставропольского края пастбища преимущественно приурочены к КумоМанычской впадине и протягиваются вдоль Чограйского водохранилища в северной части района.

Общая площадь пастбищ в 2018 году в Буденновском районе составила 22030 га, что составляет порядка $86 \%$ от площади пастбищных угодий в 1990 году. В Арзгирском районе площадь пастбищ - 76660 га в 2018 г., что меньше площади пастбищ в 1990 году на 13,6\%. За 28-летний период времени площади в Буденновском районе сократились на 6020 га, а в Арзгирском районе на 12110 га. В Арзгирском районе за 28-летнй период значительные площади угодий претерпели изменения в пределах Кумо-Манычской впадины. Также значительно уменьшения плошади пастбищ около поселка Степного. В Буденновском районе в большей степени подверглись изменениям пастбища, расположенные восточнее долины р. Кумы. По степени проявления водной эрозии, исследуемые районы входят в пятерку районов Ставропольского края наиболее подверженных эрозионным процессам.

Выводы: В Буденновском и Арзгирском районах Ставропольского края вы явлено сокращение площадей пастбищ за исследуемый период. Наиболее быстро трансформировались пастбища в период с 2010 по 2018 г. Физико-географические особенности районов находят свое отражение в размере участков пастбищ. Трансформируемые пастбиша располагаются в долинах рек и балок, что в будущем может сказаться на развитии эрозионных процессов на землях сельскохозяйственного назначения.

Ключевые слова: трансформация, пастбище, космический мониторинг, ГИС-технологии, деградация, рациональное землепользование. 
Skripchinskiy A.V., Antonov S.A.

\section{SPACE MONITORING OF PASTURES OF THE EASTERN REGIONS OF THE STAVROPOL TERRITORY}

Introduction:

Materials and methods of research:

Results and discussion:

Conclusions:

Key words:
As a result of the shortage of arable land in the Stavropol region is the transformation of agricultural land. It is possible to identify the extent of plowing pastures on the basis of spatial and temporal analysis of agricultural land through geographic information systems using space information.

visual decoding of pastures was carried Out on the basis of data from Landsat series spacecraft in the period from January 1990 to December 2018. Clarification of the identified pasture areas was made using index images of the NDVI coefficient.

In Budyonnovsk district of the Stavropol territory pastures are located primarily along river valleys. In the Arzgir district of Stavropol Krai, pastures are mainly confined to the Kumo-Manych depression and stretch along the Chograi resenoir in the Northern part of the district.

The total area of pastures in 2018 in Budennovsky district amounted to 2,230 hectares, which is about $86 \%$ of the area of pastures in 1990. In the Argir district, the area of pastures is 76660 hectares in 2018 , which is $13.6 \%$ less than the area of pastures in 1990. A28-year time period square in Budyonnovsk the district decreased by 6020 ha, and in Argirskogo district at 12110 ha. Arzgirskogo in the district for 28 years period considerable areas of land have undergone changes in the boundaries of the Kuma-Manych depression. Also significantly reducing the area of pastures near the village of Steppe. In the Budennovsky district, pastures located to the East of the Kuma river valley have undergone changes to a greater extent. According to the degree of manifestation of water erosion, the study areas are among the five districts of the Stavropol territory most prone to erosion processes.

In Budennovsk and Arzgirskogo districts of the Stavropol territory revealed a reduction of pastures during the study period. The most rapidly transformed pastures in the period from 2010 to 2018 . Physical and geographical features of the areas are reflected in the size of pasture areas. Transformable pastures are located in the valleys of rivers and gullies, which in the future may affect the development of erosion processes on agricultural land.

transformation, pasture, space monitoring, GIS technologies, degradation, rational land use.

\section{Введение}

Проблематике рационального использования земель как на региональном, так глобальном уровнях на основе данных дистанционного зондирования посвящено немало работ. [3, 7, 9]. Исследования проводятся на основе разнообразных материалов космической съемки различного пространственного и временного разрешения.

В Ставропольском крае достаточно остро стоит вопрос о рациональном использовании земельных ресурсов. Использование земель для целей сельскохозяйственного производства связано с целым рядом негативных 
явлений. Некоторые из них связаны с распашкой естественных кормовых угодий (пастбищ). Обусловлены эти процессы растущими объемами производства зерновой продукции и снижением объемов продукции животноводства. По данным специалистов Министерства сельского хозяйства Ставропольского края распахано незаконно более чем сто тысяч гектаров пастбиш [8]. В краевом министерстве сельского хозяйства функционирует геоинформационная система «Распределение земель сельскохозяйственного назначения в Ставропольском крае», данные которой свидетельствуют о факте отсутствия неиспользуемой пашни, что порождает ее дефицит для сельхозпроизводителей. Одновременно отмечается, что на основе спутниковых данных выявлено, что в крае используется на 251406,4 га больше пашни, чем по данным Росстата [4]. По данным дистанционного зондирования Земли 2015 г. площадь пашни в Ставропольском крае на 332,2 тыс. га превышала официальные данные статистики [13].

Выявление трансформированных угодий основано на пространственно-временном анализе сельскохозяйственных угодий посредством геоинформационных систем на основе данных космической съемки. Космическая информация является объективным и достоверным источником, позволяющая оценить состояние территории, как в прошлом, так и в настоящее время. В настоящее время вопросы изучения изменения растительного покрова и естественных кормовых угодий на основании данных дистанционного зондирования рассматриваются достаточно широко $[1,5,6]$.

\section{Материалы и методы исследования}

Для выявления трансформированных сельскохозяйственных угодий используются мозаики космических снимков и прямые дешифровочные признаки вкупе с определенным набором спектральных каналов, включающим ближние инфракрасные каналы и красный. Фактически обязательными являются показатели вегетационных индексов, на основе которых производится оценка состояния пастбиш $[1,5,6]$.

В основе производимого исследования лежат данные космической съемки с космических аппаратов серии Landsat, со спутников Landsat - 5 и Landsat -8 , полученные из архива Американской Геологической Службы (USGS) [12]. Это объясняется единым пространственным разрешением тематических каналов (30 метров) и идентичностью спектральных каналов. Временной период исследования охватывает период с января 1990 года по декабрь 2018 г. на территорию Буденновского и Арзгирского районов Ставропольского края.

Пастбища и сенокосы выявлялись путем визуального дешифрирования. Преимущественно использовались комбинации «искусственные цвета» 
и «естественные цвета». Для уточнения выявляемых территорий пастбищ нами использовались индексные изображения коэффициента NDVI [11], позволяющие скорректировать полученные результаты. Часть полигонов пастбищных угодий создавалась по индексному изображению, созданному на основе индекса NDVI. Такой подход использовался в том случае, когда результаты дешифрирования не позволяли однозначно выявить определенный тип угодий по указанным ранее комбинациям каналов.

При отсутствии подобной детальной информации выделение трансформированных пастбищ нами первоначально производилось на основе данных 2018 г, поскольку данные космические снимки имеют наиболее высокое радиометрическое разрешение, а соответственно и качество изображений. Все работы производились в программах ScanEx Image Processor и QGIS.

В обобщенном виде технологию выявления трансформированных пастбищ на основе данных Landsat можно представить следующим образом:

1. Получение данных с учетом сезонных особенностей.

2. Векторизация пастбищ по выбранным комбинациям каналов.

3. Создание индексных изображений на основе коэффициента NDVI.

4. Верификация полученных данных.

5. Создание «опорного» векторного слоя пастбищ.

6. Сопоставление «опорного» векторного слоя пастбищ с новым сроком съемки.

7. Создание картографических материалов произошедших изменений.

\section{Результаты \\ и их обсуждение}

В Буденновском районе Ставропольского края пастбища располагаются в основном по долинам рек Мокрая Буйвола, Томузловка, Горькая Балка и Кума. Преимущественно пастбища приурочены к балкам и оврагам, тогда как на невысоких платах расположены пашенные угодья. В Арзгирском районе Ставропольского края пастбища преимущественно приурочены к Кумо-Манычской впадине и протягиваются вдоль Чограйского водохранилища в северной части района. Здесь пастбища имеют линейное расположение, также простираясь вдоль речных балок. Значительная часть пастбиш приурочена к небольшим населенным пунктам, располагаясь вокруг них (рис 1). Подобное расположение пастбищ сложилось исторически, пос- 


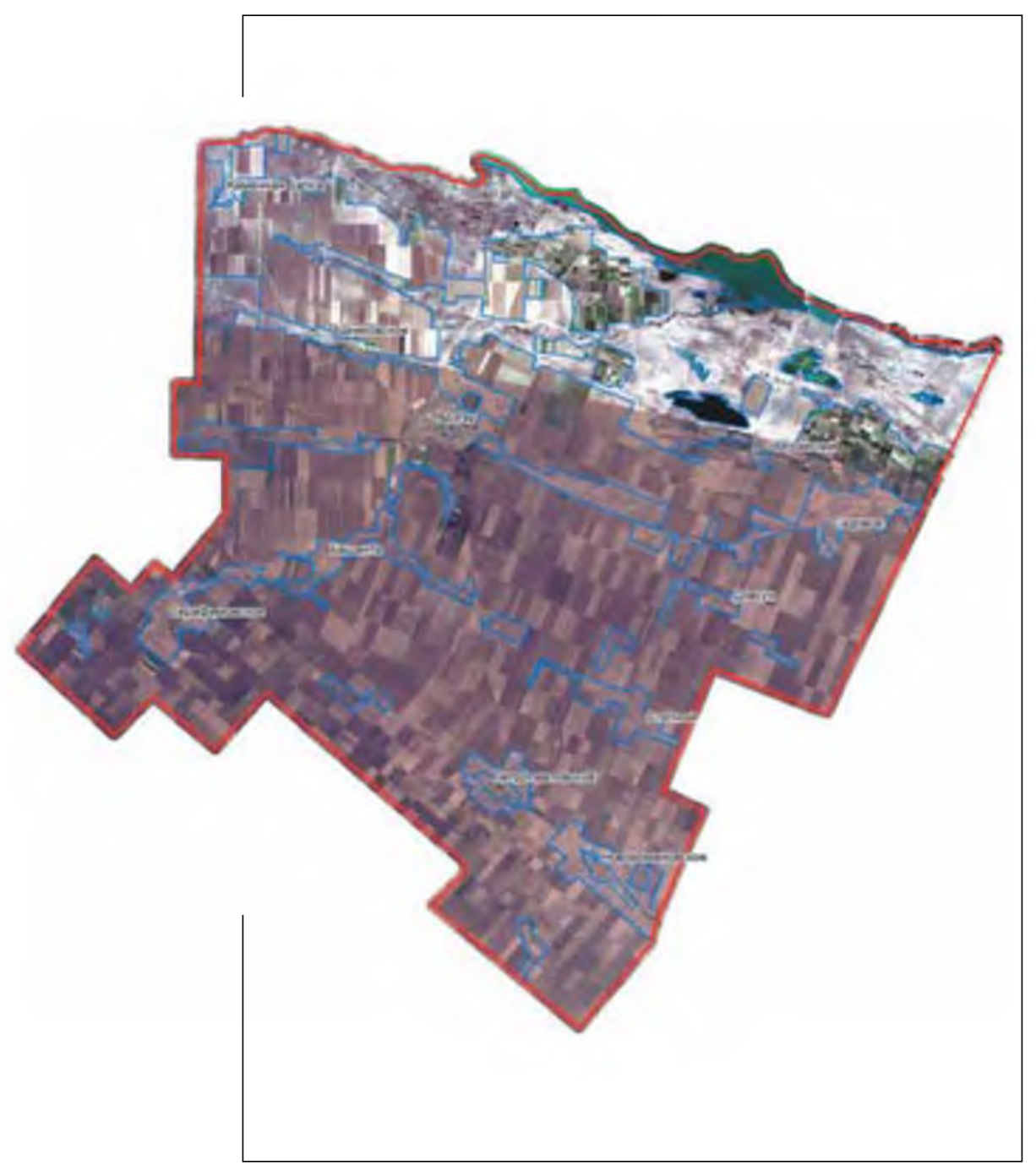

Pис. 1.

Пастбища Арзгирского района по состоянию на 1990 год (мозаичный космофотоплан).

Fig. 1. Pastures of the Argirsky region as of 1990 (mosaic space photoplan) 


\begin{tabular}{|c|c|c|c|c|c|c|}
\hline \multirow[t]{2}{*}{ Год } & \multicolumn{3}{|c|}{ Буденновский район } & \multicolumn{3}{|c|}{ Арзгирский район } \\
\hline & $\begin{array}{l}\text { Площадь } \\
\text { (га) }\end{array}$ & $\begin{array}{l}\text { Изменение } \\
\text { по сравнению } \\
\text { к } 1990 \text { г. (га) }\end{array}$ & \begin{tabular}{|l|} 
Изменение \\
по сравнению \\
к 1990 г. (\%)
\end{tabular} & \begin{tabular}{|l|}
$\begin{array}{l}\text { Площадь } \\
\text { (га) }\end{array}$ \\
\end{tabular} & \begin{tabular}{|l|} 
Изменение \\
по сравнению \\
к 1990 г. (га)
\end{tabular} & \begin{tabular}{|l|} 
Изменение \\
по сравнению \\
к 1990 г.(\%)
\end{tabular} \\
\hline 1990 & 28050 & 0 & 0 & 88770 & 0 & 0 \\
\hline 2000 & 27200 & -850 & $-3,0$ & 86373 & -2397 & $-2,7$ \\
\hline 2010 & 25520 & -2530 & $-6,2$ & 82201 & -6569 & $-7,4$ \\
\hline 2018 & 22030 & -6020 & $-13,7$ & 76660 & -12110 & $-13,6$ \\
\hline
\end{tabular}

кольку в частных хозяйствах держали крупный рогатый скот, который выпасали вблизи населенных пунктов.

Общая площадь пастбищ в 2018 году в Буденновском районе составила 22030 га, что составляет порядка $86 \%$ от площади пастбищных угодий в 1990 году. В Арзгирском районе площадь пастбищ составляет 76660 га в 2018 г., что меньше площади пастбищ в 1990 году на 13,6\% (табл. 1). Общий тренд изменения пастбищных угодий характеризуется отрицательной динамикой площадей. За 28 -летний период времени площади в Буденновском районе сократились на 6020 га, а в Арзгирском районе на 12110 га. Наиболее быстрыми темпами сокращались площади пастбищных угодий в период с 2010 по 2018 год.

Пространственный анализ трансформированных пастбищных угодий за 28-летнй период на территории Арзгирского района Ставропольского края позволяет заключить следующие. Значительные площади угодий претерпели изменения в пределах Кумо-Манычской впадины, где большие площади целинных пастбищ обусловлены физико-географическими особенностями территории. Важно отметить, факт значительного уменьшения плошади пастбиш около поселка Степного. Преимущественно трансформированные пастбищные угодья располагаются в центральной и северной частях района. В 1990г. было выделено 23 контура пастбищных угодий, максимальная площадь одного контура составляла 56574 га, который приурочен к Кумо-Манычской впадине. К 2018 г. его площадь уменьшилась до 53163 га. Средняя площадь контуров пастбищных угодий составила в 1990 г. -3744 га, а в 2018 г. -3338 га. 

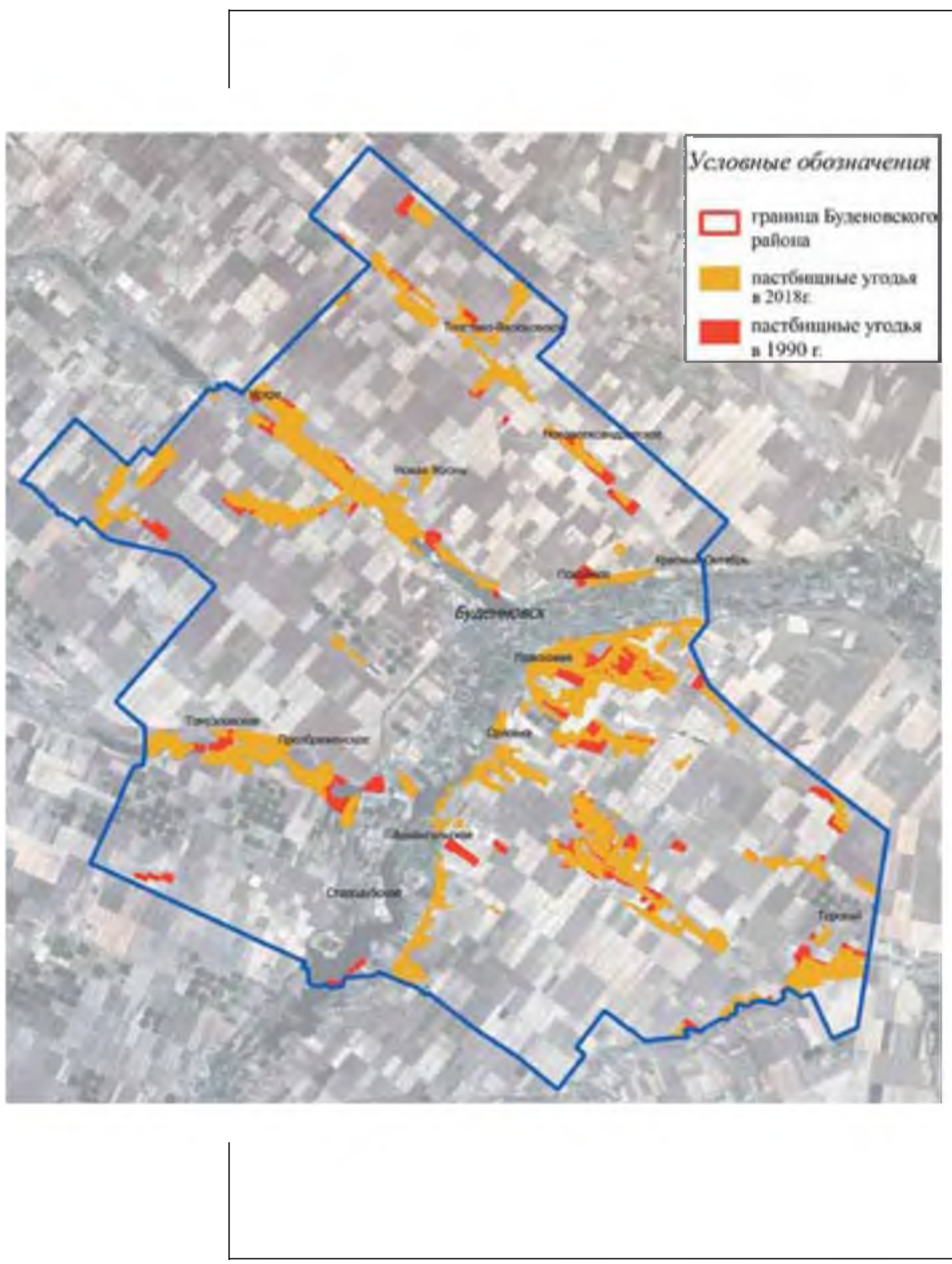

Pис. 2.

Трансформированные пастбища Буденновского района в период с 1990 по 2018 год (космофотоплан) на основе космического снимка Landsat - 5 от 04.08.1991 г.

Fig. 2. Transformed pastures of the Budennovsky district in the period from 1990 to 2018 (kosmofotoplan) based on the Landsat satellite image -5 of 04.08 .1991 . 
Небольшие плошади трансформации пастбищных угодий отмечены в окрестностях сел Петропавловского и Новоромановского. Факт сокращения пастбиш около сельских населенных пунктов особенно важен, поскольку лишает возможности местных жителей содержать скот для личного потребления, что является важной проблемой для сельского населения, особенно в настоящее время, когда наблюдается его отток в города.

Пастбища Буденновского района Ставропольского края в своем большинстве имеют линейную форму, простираясь с северо-запада на юго-восток. Общее количество выделенных контуров по состоянию на 1990 г. составляет 113, тогда как по состоянию на 2018 г. - 143, что свидетельствует о большей степени общности пастбищных угодий ранее.

В большей степени подверглись изменениям пастбища, расположенные восточнее долины р. Кумы (рис. 2). Всего было выделено 214 объекта, максимальная площадь отдельных контуров составила более 500 га. При среднем значении отдельных контуров трансформированных пастбищ в 60,6 га, стандартное отклонение составляет 58,2 га, что свидетельствует о широком диапазоне значений площадей анализируемых участков. Ранжирование всех выявленных участков по естественным группам позволило заключить, что более $60 \%$ характеризуются площадью от нескольких до 50 гектаров. Площадь более 100 га имеют более $20 \%$ всех трансформированных участков. Преимущественно трансформированные пастбища приурочены к долинам рек и эрозионным формам рельефа. Поскольку они распахиваются, то увеличивается риск возникновения и развития эрозионных процессов на землях сельскохозяйственного назначения. По материалам космической съемки 2015 г. общая протяженность линейной водной эрозии на пашне Буденновского района составляла - 2363 км, а на пашне Арзгирского района - 1943 км [2]. По степени проявления водной эрозии, исследуемые районы входят в пятерку районов Ставропольского края наиболее подверженных данному виду деградации. В основном деградированные участки пашни имеют большую крутизну склона, что усугубляет развитие водной эрозии и с высокой долей вероятности ранее эти участки относились к сенокосам и пастбищам.

\section{Выводы}

1. Исследуемые районы характеризуются общей динамикой сокращения пастбищ в период с 1990 по 2018 г. Наиболее активно площади пастбищных угодий сокращалась в период с 2010 по 2018 г.

2. В Арзгирском районе пастбища представлены более крупными земельными участками, чем в Буденновском райо- 
не, что связано с физико-географическими особенностями района.

3. Преимущественно трансформированные пастбища приурочены к долинам рек и балок, что в будущем будет способствовать развитию эрозионных процессов.

\section{Библиографический список}

1. Алдошин С.С. Космический мониторинг сельскохозяйственного землепользования Калужской области / С.С. Алдошин, Е.Н. Горбачева, С.Г. Мышляков [и др.] // Геопрофри. 2015. № 4. C. 10-14.

2. Антонов С.А. Оценка развития процессов водной эрозии на территории агроландшафтов Ставропольского края и их влияние на продуктивность / С.А. Антонов, А.Н. Есаулко, М.С. Сигида [и др.] // Вестник АПК Ставрополья. 2018. № 1 (29). С.67-72.

3. Барталев С.А. Исследования и разработки ИКИ РАН по развитию методов спутникового мониторинга растительного покрова / С.А. Барталев, Е.А. Лупян // Современные проблемы дистанционного зондирования Земли из космоса. 2013. Т. 10. №1. C. $197-114$.

4. Государственный мониторинг земель сельскохозяйственного назначения. [Электронный ресурс] - Режим доступа: [https:// www.akkor.ru/sites/default/files/i.s. kozubenko.pdf] на 01.06.2019.

5. Елсаков В.В. Современные изменения растительного покрова пастбищ северного оленя Тиманской тундры по результатам анализа данных спутниковой съёмки / В.В.Елсаков, В.М.Щанов // Современные проблемы дистанционного зондирования Земли из космоса. 2019. Т. 16. №2. С. 128-142.

6. Золотокрылин А.Н. Оценка экологического состояния «норма» аридных пастбищ по геоботаническим и MODIS данным / А.Н. Золотокрылин, И.А. Трофимов, Т.Б. Титкова // Современные проблемы дистанционного зондирования Земли из космоca. 2014. T. 11. № 2. C. 197-207.

7. Иванов М.А. Методика картографирования динамики пахотных угодий в бассейнах рек Европейской территории России за период 1985-2015 гг./ М.А. Иванов, А.В. Прищепов, В.Н. Голосов [и др.] // Современные проблемы дистанционного зондирования Земли из космоса. 2017. Т. 14. № 5. С. 161-171.

8. Ответственность за распашку пастбищ будет ужесточена. [Электронный ресурс] - Режим доступа: [http://www.stapravda. ru/20161109/otvetstvennost_za_raspashku_pastbisch_budet_ uzhestochena_97835.html] на 01.06.2019. 
9. Плотников Д.Е. Автоматическое распознавание используемых пахотных земель на основе сезонных временных серий восстановленных изображений Landsat / Д.Е. Плотников, П.А. Колбудаев, С.А. Барталев [и др.] // Современные проблемы дистанционного зондирования Земли из космоса. 2018. Т. 15. №2. C. $112-127$.

10. Савин И.Ю. О влиянии засоренности на NDVI посевов ярового ячменя, определяемый по спутниковым данным MODIS / И.Ю. Савин, П.А. Докукин, Ю.И. Вернюк [и др.] // Современные проблемы дистанционного зондирования Земли из космоса. 2017. T. 14. № 3. С. 185-195.

11. Черепанов А.С. Спектральные свойства растительности и вегетационные индексы /А.С. Черепанов, Е.Г. Дружинина. М.: Геоматика. 2009. № 3(4). С.28-32.

12. Landsat Satelite Archives // USGS Earthexplorer. 2018. [Электронный ресурс] - Режим доступа: [http://earthexplorer.usgs.gov] на 05.06.2019.

13. Trukhachev V.I., Esaulko A.N., Antonov S.A., Loshakov A.V., Sigida M.S. Water Erosion Monitoring On The Territory OfAgrolandscapes Stavropol Territory By Remote Methods // Research Journal of Pharmaceutical, Biological and Chemical Sciences. NovemberDecember 2018. №9(6). pp. 1766-1769.

\section{References}

1. Aldoshin S.C. Space monitoring of agricultural land use of the Kaluga region / S.C. Aldoshin, E.N. Gorbacheva, S.G. Myshlyakov [i dr.] // Geoprofi. 2015. № 4. S. 10-14.

2. Antonov S.A. Otsenka razvitiya protsessov vodnoy erozii na territorii agrolandshaftov Stavropol'skogo kraya i ikh vliyaniye na produktivnost' / S.A. Antonov, A.N. Yesaulko, M.S. Sigida [i dr.] // Vestnik APK Stavropol'ya. 2018. № 1 (29). S. 67-72.

3. Bartalev S.A. Research and development of IKI of RAS on the development of methods for satellite monitoring of vegetation cover $I$ S.A. Bartalev, E.A. Lupyan // Sovremennye problemy distancionnogo zondirovaniya Zemli iz kosmosa. 2013. T. 10. №1. S. 197-114.

4. Gosudarstvennyy monitoring zemel' sel'skokhozyaystvennogo naznacheniya. [Elektronnyy resurs] - Access Mode: [https://www.akkor.ru/sites/default/files/i.s. kozubenko.pdf] on 01.06.2019.

5. Elsakov V.V. Modern changes in vegetation cover of Timan tundra reindeer pastures based on analysis of satellite imagery data / V.V. Elsakov, V.M. Shchanov // Sovremennye problemy distancionnogo zondirovaniya Zemli iz kosmosa. 2019. T. 16. №2. S. 128-142.

6. Zolotokrylin A.N. Assessment of the ecological state "norm" of 
arid pastures according to geobotanical and MODIS data. / A.N. Zolotokrylin, I.A. Trofimov, T.B. Titkova // Sovremennye problemy distancionnogo zondirovaniya Zemli iz kosmosa. 2014. T. 11. № 2. S. 197-207.

7. Ivanov M.A. Methods for mapping the dynamics of arable land in the river basins of the European territory of Russia for the period 1985-2015 / M.A. Ivanov, A.V. Prishchepov, V.N. Golosov [i dr.] // Sovremennye problemy distancionnogo zondirovaniya Zemli iz kosmosa. 2017. T. 14. № 5. S. 161-171.

8. Otvetstvennost' za raspashku pastbishch budet uzhestochena. [Elektronnyy resurs] - Access Mode: [http://www.stapravda. ru/20161109/otvetstvennost_za_raspashku_pastbisch_budet_ uzhestochena_97835.html] on 01.06.2019.

9. Plotnikov D. E. Automatic recognition of arable land used based on seasonal time series of reconstructed Landsat images / D.E. Plotnikov, P.A. Kolbudaev, S.A. Bartalev [i dr.] // Sovremennye problemy distancionnogo zondirovaniya Zemli iz kosmosa. 2018. T. 15. №2. S. $112-127$.

10. Savin I.YU. On the effect of debris on the NDVI of spring barley crops, as determined by MODIS satellite data /I.YU. Savin, P.A. Dokukin, YU.I. Vernyuk [i dr.] // Sovremennye problemy distancionnogo zondirovaniya Zemli iz kosmosa. 2017. T. 14. № 3. S. 185-195.

11. Cherepanov A.S. Spectral properties of vegetation and vegetation indices / A.C. Cherepanov, E.G. Druzhinin. M.: Geomatics. 2009. №3 (4). C. 28-32.

12. Landsat Satelite Archives // USGS Earthexplorer. 2018 [Elektronnyy resurs] - Access Mode: [http://earthexplorer.usgs.gov] on 01.06.2019.

13. Trukhachev V.I., Esaulko A. N., Antonov S.A., Loshakov A.V., Sigida M.S. Water Erosion Monitoring On The Territory Of Agrolandscapes Stavropol Territory By Remote Methods // Research Journal of Pharmaceutical, Biological and Chemical Sciences. NovemberDecember 2018. №9(6). Pp. 1766-1769.

Рукопись поступила в редакцию 05.05.19, принята к публикации 01.06.19. 


\section{6 авторах}

Скрипчинский Андрей Владимирович, кандидат географичческих наук, доцент кафедры социально-экономической географии, геоинформатики и туризма, института математики и естественных наук, Северо-Кавказского федерального университета. Scopus ID: 0, Researcher ID: S-1669-2018. Телефон +7905-412-07-22, E-mail: ron1975@list.ru.

Антонов Сергей Анатольевич, кандидат географических наук, ведущий научный сотрудник, заведующий лабораторией ГИС-технологий, ФГБНУ «Северо-Кавказский федеральный научный аграрный центр». Scopus ID: 0, Researcher ID: A-1325-2019. Телефон: +7903-409-38-27, e-mail: santosb@mail.ru.

\section{About the authors}

Skripchinskiy Andrey Vladimirovich. Ph.D of Geographical Sciences, associate Professor. Assistant Professor of social and economic geography, geo-Informatics and tourism, North-Caucasus Federal University, Stavropol. Scopus ID: 0, Researcher ID: S-1669-2018.

Tel.: +7905-412-07-22, E-mail: ron1975@list.ru.

Antonov Sergey Anatolyevich. Ph.D of Geographical Sciences, Leading Researcher, Head of the Laboratory GIS-technology FSBSI "NorthCaucasian Federal Scientific Agrarian Center". Scopus ID: 0, Researcher ID: A-1325-2019.

Tel: +7903-409-38-27, e-mail: santosb@mail.ru. 